
NASA
Technical
Paper
3081
June 1991
A Three-Dimensional
Finite-Element
Thermal/Mechanical
Analytical Technique
for High-Performance
Traveling Wave Tubes

Karen F. Bartos,

E. Brian Fite,

Kurt A. Shalkhauser,

and G. Richard Sharp 
NASA

Technical

Paper

3081

1991

\section{A Three-Dimensional \\ Finite-Element \\ Thermal/Mechanical \\ Analytical Technique \\ for High-Performance \\ Traveling Wave Tubes}

Karen F. Bartos,

E. Brian Fite,

Kurt A. Shalkhauser, and G. Richard Sharp

Lewis Research Center

Cleveland, Ohio 


\section{Summary}

Current research into high-efficiency, high-performance traveling wave tubes (TWT's) has led to the development of novel thermal/mechanical computer models for use with helical slow-wave structures. This report describes a three-dimensional, finite-element computer model and analytical technique used to study the structural integrity and thermal operation of a highefficiency, diamond-rod, K-band TWT designed for use in advanced space communications systems. This analysis focused on the slow-wave circuit in the radiofrequency output section of the TWT, where an inherent localized heating problem existed and where failures had been observed during earlier TWT programs. Furthermore, the new TWT and the computer model were both designed around an innovative coldcompression, or "coining," fabrication technique that shows great potential for future TWT development efforts. For this analysis, a three-dimensional, finite-element model was developed to simulate the fabrication and operation of a diamond-rod TwT. This analysis was conducted with MARC, a commercially available finite-element code, using component and material specifications consistent with actual TWT fabrication. The analysis is nonlinear owing to material plasticity introduced by the forming process and also to geometric nonlinearities presented by the component assembly configuration. The computer model was developed by using the high-efficiency, K-band TwT design but is general enough to permit similar analyses to be performed on a wide variety of TWT designs and styles. This paper presents the results of applying this analytical technique to the configuration of an actual TWT to predict its thermal and structural operating condition and its ultimate power loading. A comparison of the analytical results with test data is presented.

\section{Introduction}

A three-dimensional, finite-element analytical methodology has been developed at the NASA Lewis Research Center to facilitate the design and fabrication of traveling wave tube (TWT) slowwave structures. A traveling wave tube is a transmitter power amplifier used in many space communications systems. A typical TwT is shown in figure 1. The methodology described in this report was applied to a TWT, designated as model $953 \mathrm{H}$, developed by Hughes Aircraft Company, Electron Dynamics Division (Contract NAS3-24897). The slow-wave structure of the $953 \mathrm{H}$ TwT is shown in figure 2. The TwT helix is a copper-plated, tungsten ( 3 percent rhenium), rectangular-crosssection tape with a variable pitch. The sleeve is fabricated of Glidcop, ${ }^{1}$ a dispersion-strengthened copper with a lower creep-strain rate than pure copper. The most unique feature of the TWT is its use of thin diamond rods to support the helix in the slow-wave structure. The three diamond rods have a rectangular cross section and are spaced $120^{\circ}$ apart. The ability to use diamonds was provided by a new, cold-compression, or "coining", fabrication technique developed by Hughes (ref. 1). This new fabrication technique promises to eliminate the structural life problems encountered with the previous technique. The entire fabrication process is described in a later section.

A commercially available finite-element (FE) code, with nonlinear capability, simulated the fabrication process to provide contact pressure and contact area information at component interfaces. A nonlinear analysis was used to account for the elastic-plastic behavior of the materials during simulation of the coining technique. A three-dimensional FE analysis was chosen to allow information to be obtained along the length of the helix/diamond interface. These data were used to assess the structural and thermal integrity of the assembly. A simulated thermal flux load was applied to the surfaces of the helix to represent electron bombardment and resistive losses. An iterative solution technique was used to calculate a predicted temperature distribution for the structure while accounting for the material and geometry changes between and in the components. The analytical technique was also used to predict a failure power level by calculating an input power level required to reach a predetermined temperature in the TWT helix coating. This temperature represents the onset of irreversible failure due to plastic deformation. Through use of this methodology, material changes and component sizes for the TWT can be iterated on the computer, thus eliminating the need for time-consuming trial-and-error testing and greatly reducing program costs. In this report, analytical and test results for four cases are presented: (1) dimensional correlation of the coining fabrication technique; (2) comparisons of predicted power capacity to TWT breadboard test data; (3) simulation of TWT normal thermal operating conditions; and (4) prediction of a TWT failure power level.

\footnotetext{
'Glidcop is a trademark of Glidden Metals, 1468 W. 9th St., Cleveland, $\mathrm{OH}, 44113$
} 


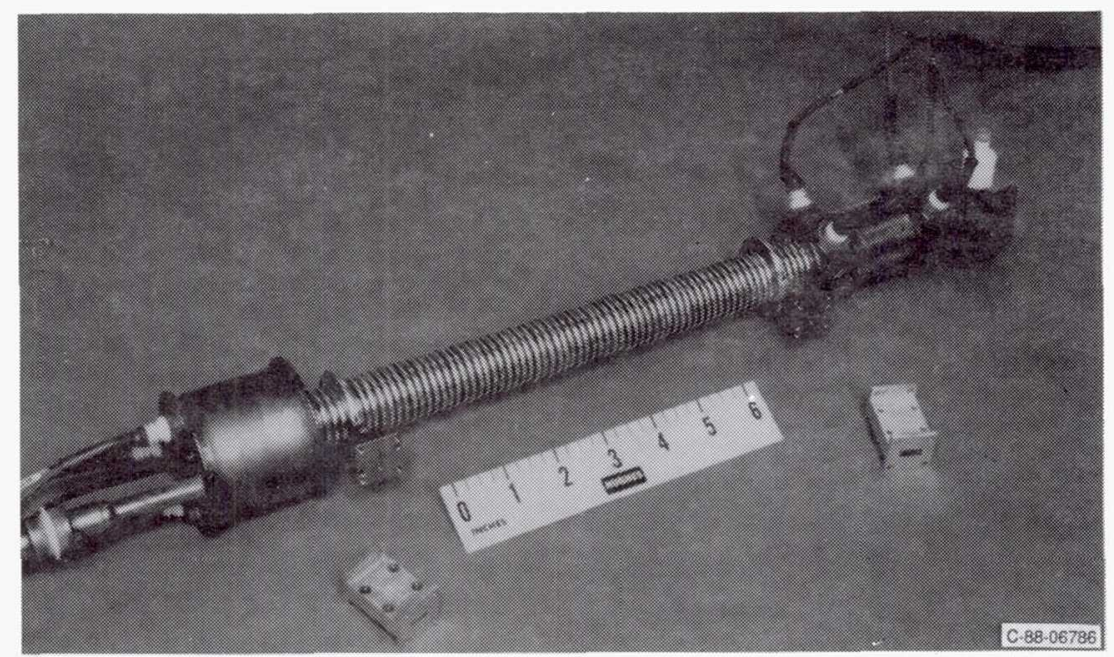

Figure 1.-Prototype of $953 \mathrm{H}$ traveling wave tube.

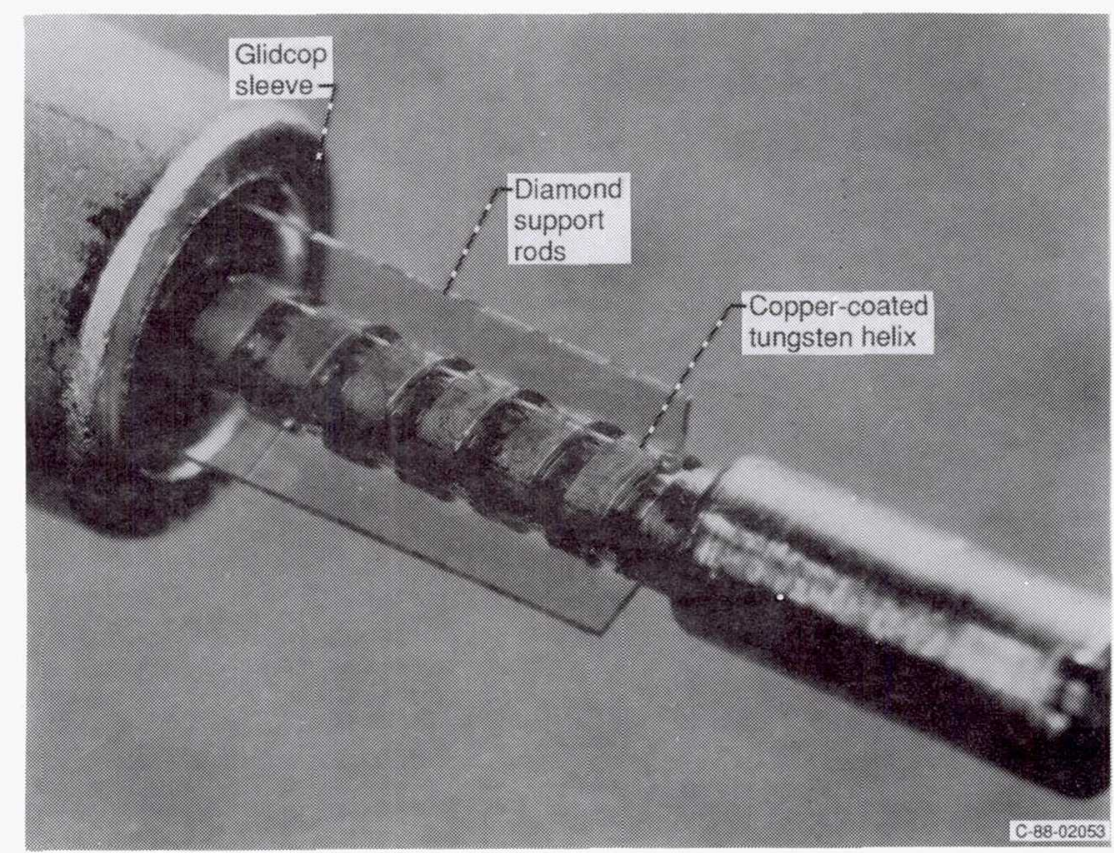

Figure 2.-Partially assembled $953 \mathrm{H}$ slow-wave structure.

\section{Background}

As terrestrial and space communications systems continue to grow in capability and performance, tighter and more ambitious specifications are placed on the components within the communications system, including the transmitter power amplifier. In many communications systems the transmitter amplifier is a traveling wave tube (TWT), which offers the advantages of high radiofrequency (RF) output power, wide signal bandwidth, and high electrical efficiency. In the space environment these attributes are even more important, in that the primary power and heat-sinking capabilities of the space platform are both limited and expensive.

In an effort to further extend the capabilities of traveling wave tubes, NASA has been conducting an extensive research program investigating novel component designs that offer significant advantages in TWT performance and efficiency. These designs include the multistage depressed collector, the dynamic velocity-tapered helix, advanced collector electrode materials, ion-textured electrode surface treatments, and the use of low-loading dielectric support rods. As a complement to this work, a research and development contract was 
established to examine the integration of all of these designs into a single high-performance traveling wave tube with an efficiency goal of 60 percent at an operating frequency of $20 \mathrm{GHz}$ (ref. 2).

As TWT design and fabrication technologies continued to mature through the 1980's, the RF output power levels and performance of $20-\mathrm{GHz}$ helix TWT's increased significantly. In order to deal with the increased power and the resultant high thermal loads, research efforts were directed at the improvement of heat transfer paths from the helix to the TWT's surrounding support structure. As a result, researchers began to look beyond the more conventional materials (beryllia and boron nitride) toward diamond for use as the helix support rods (see fig. 2). Diamond's high thermal conductivity and high compressive strength allowed the support rods to be thinned to very small dimensions while continuing to provide high contact pressure and good heat transfer characteristics. Additionally, the thin profile of the diamond support rods imposed very low dielectric loading on the RF signal, improving the overall TWT efficiency.

Early attempts (ref. 3) at integrating diamond into the helix slow-wave structure resulted in only marginal success with existing fabrication technology. The early diamond TWT's were assembled by using a heat-shrink process, in which the outer sleeve of the slow-wave structure was heated to increase its inner diameter. The helix-and-rod assembly was then inserted into the sleeve and the structure was permitted to return to room temperature, resulting in radial compressive forces being applied to the helix-and-rod assembly. In order to avoid fracturing the diamond rods in this process, a molybdenum/ zirconium-copper alloy backing strip was applied along the length of each support rod, both to act as an interface medium and to assist in the assembly. Unfortunately, during highpower operation of the TWT, the backing strip plastically deformed, degrading the heat transfer from the helix to the sleeve. This resulted in a rapid escalation of helix temperatures, a corresponding drop in RF output power, and a high probability of catastrophic TWT failure. Because the area in contact at each interface is crucial in maintaining a thermal path for conducting heat away from the helix, each interface must be carefully investigated and analyzed. The need to predict the integrity of the thermal path was therefore a major impetus for developing a TWT thermal/structural analytical methodology. The benefit of using a computational process to evaluate various TWT designs is most apparent when considering the high fabrication costs associated with the materials and the quantity of parts required to iteratively size components for proper fit. Specifically, use of materials such as natural diamonds makes the sizing process extremely expensive if several design iterations are needed.

\section{Fabrication Process}

Understanding the analysis of the 953H TWT requires knowledge of the steps involved in its manufacture. The first step of the actual fabrication process was to join the diamond support rods to the helix (see fig. 2). Because naturally occurring diamonds are not generally of sufficient size to span the entire length of the slow-wave structure, segments of equal thickness and height were placed end-to-end to form each of the three diamond rods. An adhesive was used to temporarily affix the diamond support rods onto the helix to permit handling prior to coining. Once set, the diamond-support-rod-and-helix assembly was inserted into the gold-plated Glidcop sleeve. This assembly was then placed into a coining die (see fig. 3) and

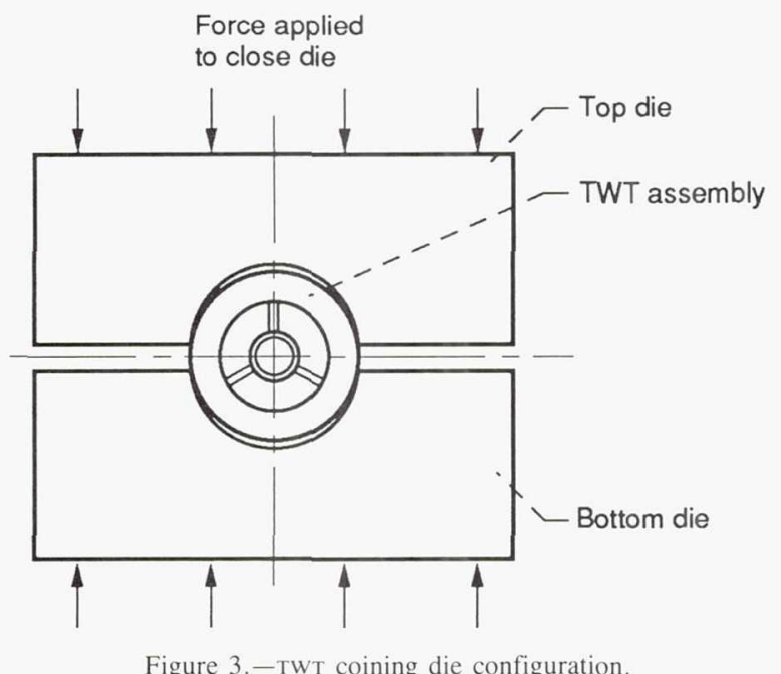

the die was closed, at room temperature, with a very high compressive force. In an effort to obtain uniform radial compression, the TWT was actually placed in the die and compressed three times. The TWT was rotated $120^{\circ}$ for each compression. This was done to account for eccentricity and surface anomalies that occur between parts because of tolerances and forming operations. After coining was completed, the TWT was submersed in a solvent bath to remove the adhesive that initially positioned the diamond rods. The coined TWT was then joined to the exterior assembly (pole piece and magnet, see fig. 4) components by means of a sintering process. The final step of the fabrication process was a bakeout. In the bakeout the TWT assembly was slowly raised from room temperature to $500{ }^{\circ} \mathrm{C}$, held there for two to three days, and then slowly cooled back down to room temperature. A flow chart depicting these fabrication steps is shown in figure 5 . 


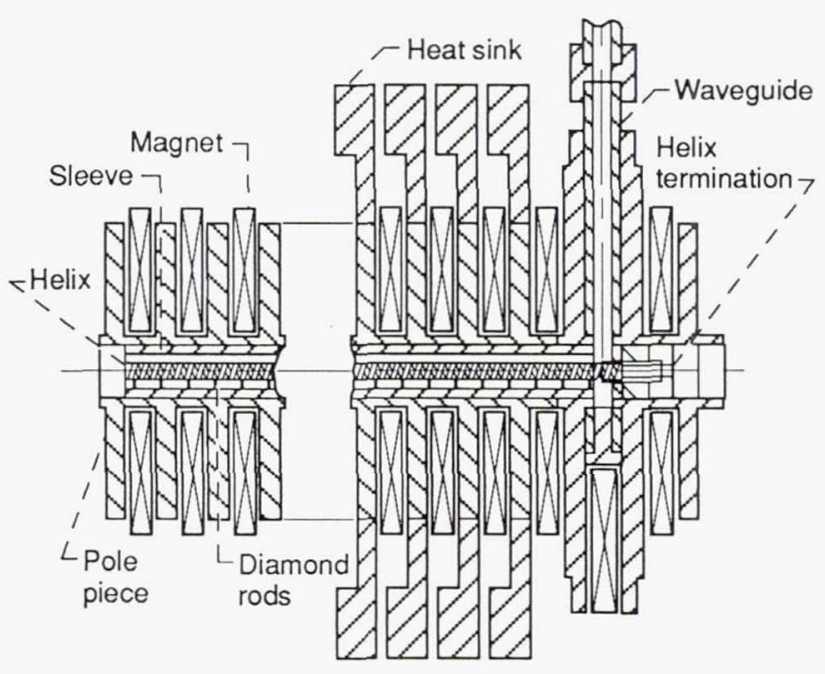

Figure 4.-Cross section of $953 \mathrm{H}$ output circuit.

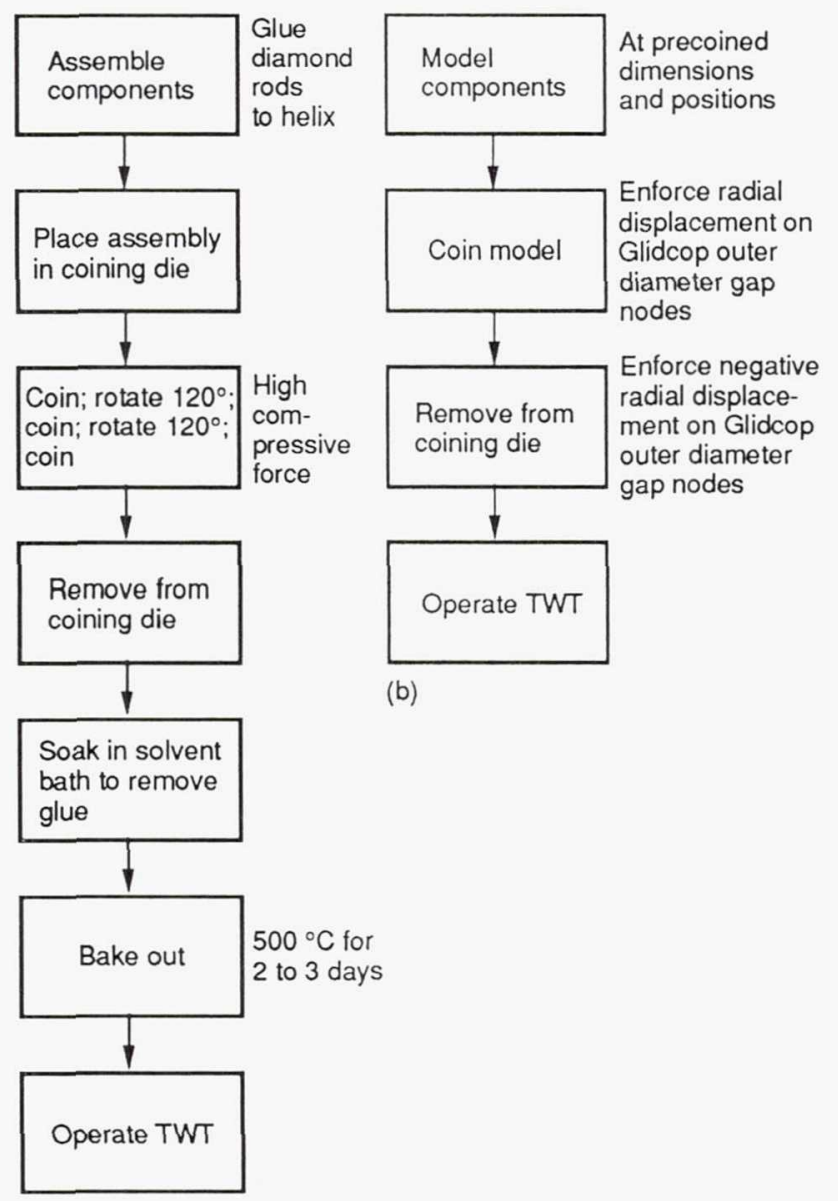

(a)

(a) Physical fabrication process.

(b) Analytical fabrication process.

Figure 5.-Comparison of physical and analytical fabrication processes.

\section{Analytical Methodology}

\section{Three-Dimensional Finite-Element Model}

The finite-element model of the traveling wave tube consisted of a $60^{\circ}$ segment, which is the smallest possible model that still fully describes the TWT geometry and loading through the application of symmetry. Figure 6 displays the threedimensional model and the coordinate systems used. Three turns of the helix, representing the critical thermal region, were modeled to account for end effects in the TWT and to verify the boundary conditions. The model, generated on the PATRAN ${ }^{2}$ pre- and postprocessor, contained over 3100 elements and over 4000 nodes. During this analysis it was determined that mesh density was dependent on the size of local plastic regions within the component materials. A two-dimensional mesh study was completed in order to arrive at the appropriate element density and configuration. The finite-element mesh was very dense at component interfaces with elements gradually becoming larger farther away from the interface areas. Overall, the $60^{\circ}$ TWT model contained three turns of the copper-plated tungsten helix, one-half of a diamond support rod, and a $60^{\circ}$ segment of the Glidcop sleeve. The use of the cylindrical coordinate system, shown in figure 6 , simplified the application of loads and boundary conditions. The finite-element code used for this analysis was MARC ${ }^{3}$. MARC is a commercially available generalpurpose code developed mainly for nonlinear applications. The primary structural element used in the model was MARC element type 7, an arbitrarily shaped eight-node cube. This element has three degrees of freedom associated with each node and eight Gaussian integration points. It uses trilinear interpolation and is formulated for finite-strain, large-displacement analysis (ref. 4). The mechanical and thermal material properties used in the analysis are listed in tables I and II. Plasticity in the metallic components of the TWT was modeled by using nonlinear stress-strain data and an isotropic hardening rule. The stress-strain values are shown in table III. The MARC program allows the input of temperature dependence for some of the material properties. An extrapolation/interpolation averaging procedure is used to evaluate these material properties at each step of the analysis. The temperaturedependent properties used are listed in tables IV and V. Material data were included up to $400{ }^{\circ} \mathrm{C}$, but all component temperatures remained well below this value.

The overall size of the model and the complexity of the analysis led to some difficulty in applying the load needed to simulate the coining process. The RESTART (ref. 5) option within the MARC program provided a means for applying the load in small portions, or increments. The final state of that

\footnotetext{
${ }^{2}$ PATRAN is a trademark of PDA Engineering, 1560 Brookhollow Drive, Santa Ana, CA, 92705

${ }^{3}$ MARC is a trademark of MARC Analysis Research Corporation, 260 Sheridan Avenue, Palo Alto, CA, 94306.
} 


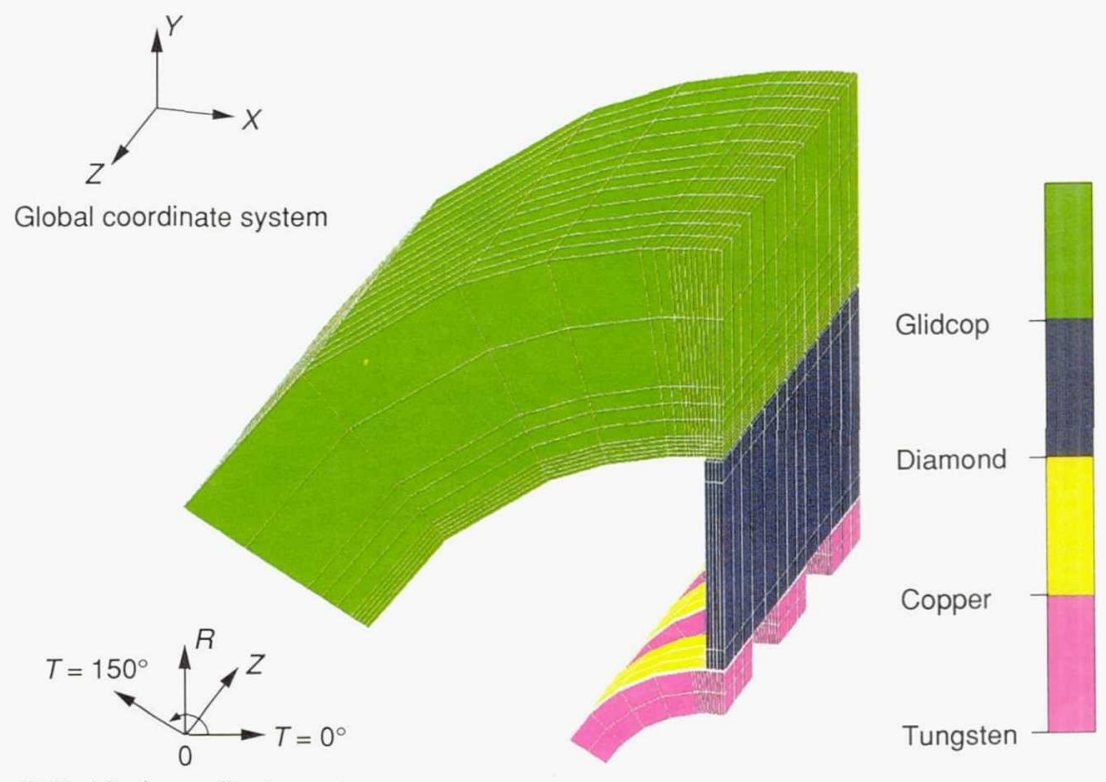

Cylindrical coordinate system

Figure 6.-Materials and coordinate systems used in $60^{\circ}$ TWT model.

TABLE I.-MATERIAL PROPERTIES

\begin{tabular}{|l|r|r|r|c|}
\hline Material & $\begin{array}{c}\text { Elastic } \\
\text { modulus, } \\
\mathrm{MN} / \mathrm{m}^{2}\end{array}$ & $\begin{array}{c}\text { Yield } \\
\text { point, } \\
\mathrm{MN} / \mathrm{m}^{2}\end{array}$ & $\begin{array}{c}\text { Poisson's } \\
\text { ratio }\end{array}$ & $\begin{array}{c}\text { Coefficient of } \\
\text { thermal } \\
\text { expansion, } \\
{ }^{\circ} \mathrm{C}^{-1}\end{array}$ \\
\hline Glidcop & 110316 & 324 & 0.33 & $18.1 \times 10^{-6}$ \\
Diamond & 1054896 & --- & .20 & 1.0 \\
Copper & 124105 & 41 & .33 & 14.3 \\
Tungsten & 406899 & 262 & .28 & 4.4 \\
\hline
\end{tabular}

TABLE II.-MATERIAL THERMAL PROPERTIES

\begin{tabular}{|l|c|r|c|}
\hline Material & $\begin{array}{c}\text { Conductivity, } \\
\mathrm{W} / \mathrm{m}^{\circ} \mathrm{C}\end{array}$ & $\begin{array}{c}\text { Density, } \\
\mathrm{kg} / \mathrm{m}^{3}\end{array}$ & $\begin{array}{c}\text { Specific } \\
\text { heat, } \\
\mathrm{kJ} / \mathrm{kg}{ }^{\circ} \mathrm{C}\end{array}$ \\
\hline Glidcop & 346 & 5.13 & 0.36 \\
Diamond & 2051 & 2.03 & 6.19 \\
Copper & 390 & 5.16 & .39 \\
Tungsten & 166 & 11.16 & .13 \\
\hline
\end{tabular}

increment was then stored and used as a starting condition for the next increment. The minimum and maximum number of recycles, or recalculations to determine changes in the stiffness matrix, within an increment had to be defined for the analysis. Convergence of an increment was controlled by a tolerance
TABLE III.-PLASTICITY DATA

\begin{tabular}{|c|c|c|}
\hline Material & $\begin{array}{l}\text { Stress, } \\
\mathrm{MN} / \mathrm{m}^{2}\end{array}$ & $\begin{array}{l}\text { Plastic } \\
\text { strain }\end{array}$ \\
\hline Glidcop & $\begin{array}{l}324 \\
344 \\
347 \\
355 \\
359 \\
362 \\
364 \\
366 \\
368 \\
369\end{array}$ & $\begin{array}{l}0 \\
.001986 \\
.003473 \\
.007916 \\
.01284 \\
.01773 \\
.02261 \\
.02745 \\
.03228 \\
.03708\end{array}$ \\
\hline Copper & $\begin{array}{r}41 \\
70 \\
133 \\
178 \\
238 \\
310 \\
372 \\
427\end{array}$ & $\begin{array}{l}0 \\
.01027 \\
.04817 \\
.09467 \\
.18177 \\
.33597 \\
.59967 \\
.79967\end{array}$ \\
\hline Tungsten & $\begin{array}{l}2637 \\
2772\end{array}$ & $\begin{array}{l}0 \\
.00945\end{array}$ \\
\hline
\end{tabular}

value entered into the program by the user. This value was a ratio of the maximum displacement change within a recycle of an increment to the displacement applied within the increment. A small tolerance value leads to increased computer time; a larger tolerance value decreases accuracy. An appro- 
TABLE IV.-TEMPERATURE EFFECTS DATA FOR STRUCTURAL MODE

\begin{tabular}{|c|c|c|c|c|c|}
\hline Material & $\begin{array}{c}\text { Temperature. } \\
{ }^{\circ} \mathrm{C}\end{array}$ & $\begin{array}{c}\text { Elastic } \\
\text { modulus. } \\
\mathrm{MN} / \mathrm{m}^{2}\end{array}$ & $\begin{array}{l}\text { Yield } \\
\text { point. } \\
\mathrm{MN} / \mathrm{m}^{2}\end{array}$ & $\begin{array}{l}\text { Poisson's } \\
\text { ratio }\end{array}$ & $\begin{array}{c}\text { Coefficient } \\
\text { of thermal } \\
\text { expansion. } \\
{ }^{\circ} \mathrm{C}^{-1}\end{array}$ \\
\hline Glidcop & $\begin{array}{r}25 \\
150 \\
300 \\
400\end{array}$ & $\begin{array}{r}110316 \\
108592 \\
102 \\
987 \\
96526\end{array}$ & $\begin{array}{l}324 \\
324 \\
300 \\
269\end{array}$ & $\begin{array}{c}0.33 \\
\downarrow\end{array}$ & $\begin{array}{c}18.1 \times 10^{-6} \\
\downarrow\end{array}$ \\
\hline Diamond & $\begin{array}{r}25 \\
150 \\
300 \\
400\end{array}$ & $\begin{array}{c}1054896 \\
\downarrow\end{array}$ & $\begin{array}{l}-\cdots- \\
---- \\
-\cdots- \\
-\cdots-\end{array}$ & $\begin{array}{c}0.20 \\
\downarrow\end{array}$ & $\begin{array}{l}1.05 \times 10^{-6} \\
1.99 \\
3.04 \\
3.40\end{array}$ \\
\hline Copper & $\begin{array}{r}25 \\
150 \\
300 \\
400\end{array}$ & $\begin{array}{ll}124 & 105 \\
121 & 347 \\
115 & 142 \\
107 & 558\end{array}$ & 41 & $\begin{array}{c}0.33 \\
\downarrow\end{array}$ & $\begin{array}{l}14.30 \times 10^{-6} \\
15.08 \\
16.35 \\
17.3\end{array}$ \\
\hline Tungsten & $\begin{array}{r}25 \\
150 \\
300 \\
400\end{array}$ & $\begin{array}{c}406790 \\
\downarrow\end{array}$ & $\begin{array}{l}2620 \\
2275 \\
2051 \\
1965\end{array}$ & $\begin{array}{l}0.284 \\
.\end{array}$ & $\begin{array}{l}4.44 \times 10^{-6} \\
4.48 \\
4.55 \\
4.60\end{array}$ \\
\hline
\end{tabular}

TABLE V.-TEMPERATURE EFFECTS DATA FOR THERMAL MODE

\begin{tabular}{|c|c|c|c|c|}
\hline Material & $\begin{array}{c}\text { Temperature, } \\
{ }^{\circ} \mathrm{C}\end{array}$ & $\begin{array}{l}\text { Conductivity, } \\
\mathrm{W} / \mathrm{m}{ }^{\circ} \mathrm{C}\end{array}$ & $\begin{array}{c}\text { Density, } \\
\mathrm{kg} / \mathrm{m}^{3}\end{array}$ & $\begin{array}{c}\text { Specific } \\
\text { heat, } \\
\mathrm{kJ} / \mathrm{kg}{ }^{\circ} \mathrm{C}\end{array}$ \\
\hline Glidcop & $\begin{array}{r}25 \\
150 \\
300 \\
400\end{array}$ & $\begin{array}{l}346 \\
335 \\
321 \\
315\end{array}$ & $\begin{array}{l}5.13 \\
\downarrow\end{array}$ & $\begin{array}{r}0.36 \\
.37 \\
.39 \\
.40\end{array}$ \\
\hline Diamond & $\begin{array}{r}25 \\
150 \\
300 \\
400\end{array}$ & $\begin{array}{r}2051 \\
1472 \\
996 \\
752\end{array}$ & $\begin{array}{l}2.03 \\
\downarrow\end{array}$ & $\begin{array}{c}6.19 \\
\downarrow\end{array}$ \\
\hline Copper & $\begin{array}{r}25 \\
150 \\
300 \\
400\end{array}$ & $\begin{array}{l}390 \\
366 \\
346 \\
335\end{array}$ & $\downarrow^{5.16}$ & $\begin{array}{r}0.39 \\
.40 \\
.41 \\
.42\end{array}$ \\
\hline Tungsten & $\begin{array}{r}25 \\
150 \\
300 \\
400\end{array}$ & $\begin{array}{l}166 \\
157 \\
144 \\
136\end{array}$ & 11.16 & $\begin{array}{r}0.13 \\
.13 \\
.14 \\
.14\end{array}$ \\
\hline
\end{tabular}

priate tolerance was determined by comparing computer run times to increment output for several different values. Any value for this ratio will introduce error in the form of out-ofequilibrium force, or residual load, and a tolerance value should be chosen to minimize this error. In order to improve solution accuracy, MARC applies the residual load calculated in each increment as a correcting force to prevent the out-ofequilibrium forces from accumulating throughout the analysis.

\section{Analytical Procedure}

A flow chart of the analytical steps is shown in figure 7 . The analysis began with the simulation of the coining fabrication process. Interface coefficients, based on contact areas and pressures, were calculated and then input to the heat transfer analysis. The heat transfer model was basically the same as the structural model used for the coining analysis. The heat transfer analysis provided a temperature distribution throughout the model. The temperature distribution was then applied to the structural/thermal analysis to determine the state of contact between components due to thermal loading. Iterations between the heat transfer analysis and the structural/ thermal analysis converged to a steady-state temperature distribution.

\section{Coining Analysis}

The steps taken to model the fabrication process of the TWT are shown in figure 5 and differ, to a slight degree, from the actual construction steps. Several fabrication steps were omitted in order to simplify the modeling procedure as well as the analysis. The analytical process began with the assembly of components, but the adhesive used to affix the diamond supports to the helix was not included. Although a small amount of glue may remain in this interface after the solvent bath, it should not be significant and was not included in the model. Next, the compression of the coining die was modeled, as well as its release. The simulation of the die closure is idealized; therefore it is only performed once in the analysis rather than three times. For the $953 \mathrm{H}$ тw the Glidcop sleeve is considered to be the component most susceptible to creep effects because of the high loads and relative softness of the material as compared with tungsten and diamond. Bakeout was not included in the analysis, since the Glidcop data indicated minimal creep effects under the time-temperature-stress conditions encountered (ref. 6).

The first step in the analytical process was the simulation of the coining fabrication technique. Several boundary conditions were imposed upon the model: zero displacement constraints in the $\theta$ direction at the $\theta=90^{\circ}$ face and the $\theta=150^{\circ}$ face, and zero displacement constraints in the $Z$ direction at the two $Z$-direction faces for the Glidcop sleeve and the diamond rod (see fig. 6). The helix boundary conditions required special consideration to prevent overconstraint of the model. The helix sections were modeled with the appropriate pitch for the critical end region of the $953 \mathrm{H}$ TWT. It was desired to minimally constrain the helix to allow longitudinal deformation and to extract information in the $Z$ direction of the model. This was accomplished through the use of a MARC option called TYING (ref. 7). The TYING option allowed degrees of freedom of a particular node to be made dependent upon the motion of another independent node existing in the model. In order to eliminate undefined terms in the stiffness matrix and restrain motion in the $Z$ direction, 


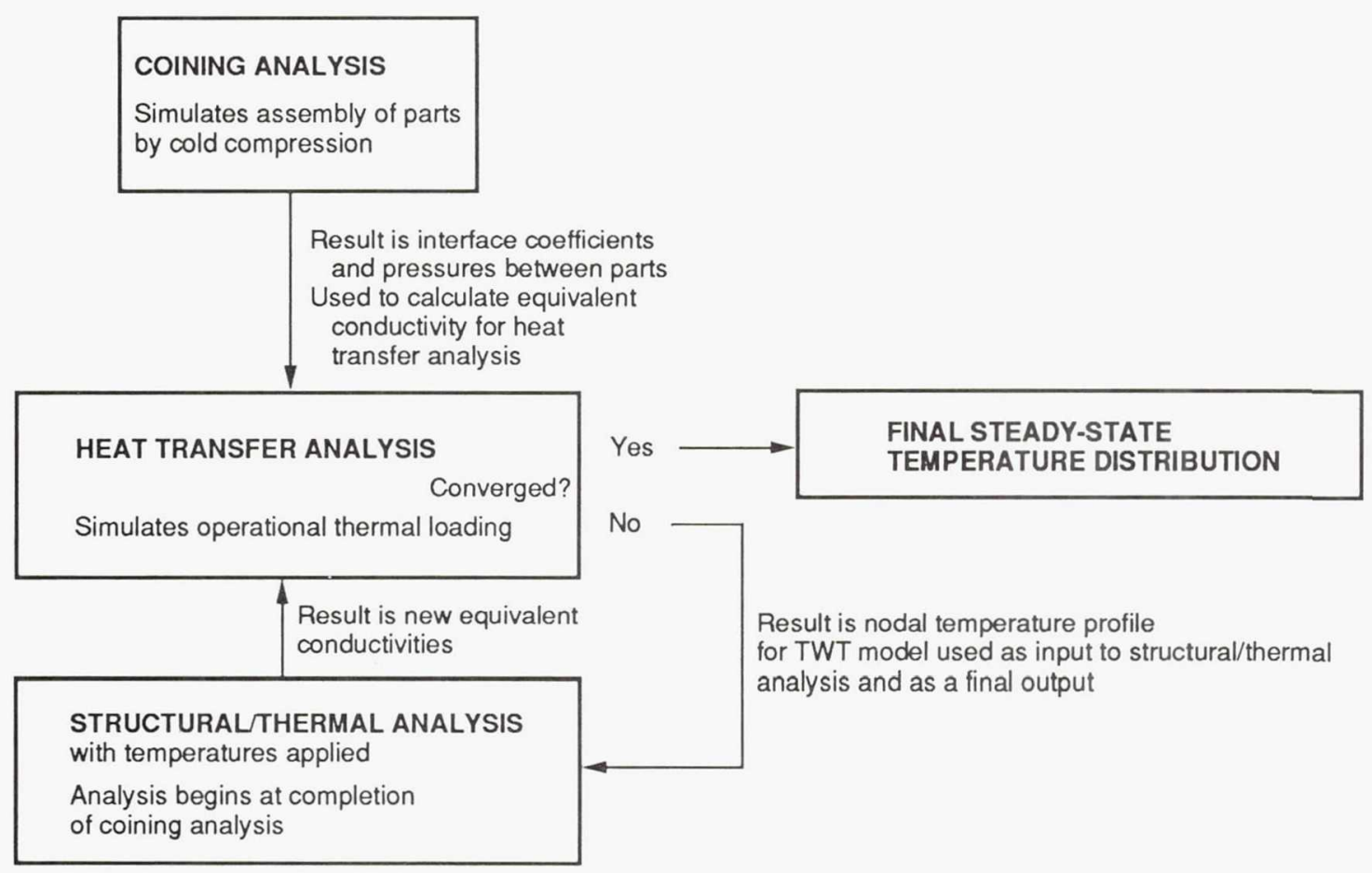

Figure 7.-Flow chart of analytical steps.

the center nodes on the helix were made dependent upon corresponding independent nodes on the diamond rod.

In general, the coining analysis consisted of two portions: loading the model (closing the coining die), and unloading the model (opening the coining die). The loading of the model was accomplished by using gap elements (MARC element type 12, ref. 8). Gap elements describe the separation (gap open) and contact (gap closed) conditions between nodes. For this application these elements act as rigid, radial links when closed, but transmit no load when open. The locations of gap elements used in the analysis are shown in figure 8. Gap elements are defined by four nodes. The first and fourth nodes have physical coordinates to define their locations on the structure. The second gap node has one degree of freedom to define the force transmitted across the gap. The third gap node defines the frictional force and frictional slip across the gap. For this analysis friction was neglected. Gap elements were used at the Glidcop sleeve/diamond rod interface because these two components were not initially in contact (before coining). One end of each gap element was located on the diamond rod and the other end on the Glidcop sleeve. Gap elements were also used in a similar manner at the diamond $\mathrm{rod} /$ helix coating interface.

Gap elements representing the coining surface were defined with existing nodes on the Glidcop sleeve outer diameter and with nodes placed at a distance of $0.0051 \mathrm{~cm}(0.002 \mathrm{in}$.) radially above each sleeve outer-diameter node (see fig. 8). The die closure was idealized by applying incremental, enforced radial displacements on these newly created nodes, which simulate the die surface. The nodes were moved radially inward, closing the outer gap elements and effectively representing a perfectly rigid die surface that has a final radial dimension equal to the closed die radial dimension. The die was assumed to be perfectly rigid, since it was made of steel and was massive when compared with the TWт being formed (see fig. 3). The die motion was idealized also, in the sense that the die actually translated and did not move radially. This effect was assumed to be small, since friction was neglected. A total displacement of $0.00775 \mathrm{~cm}$ (0.00305 in.) was imposed in seven increments. The first increment applied 60 percent of the total displacement, with increment size decreasing until the last increment added only 5 percent of the total displacement load. The loading was applied incrementally to allow the MARC program to recalculate the current increment in terms of forces, constraints, and material properties. This was necessary each time a gap changed from open to closed or closed to open during a load increment. Small incremental loads prevented the recalculations from becoming unmanageable and allowed the program to converge to a more accurate solution in a reasonable amount of computer time. The direction of closure for the coining die gap elements was defined as the radial direction. The small difference between the radial direction and the global $Y$ direction at the interior gap elements (sleeve/diamond rod and diamond rod/helix coating, see fig. 6) led to the assumption of the global $Y$ direction as the closure direction for these elements. The user subroutine GAPU (ref. 9), available within the MARC code, was used to define the gap-element closure directions. After each incremental displacement the MARC program determined gap closure status 


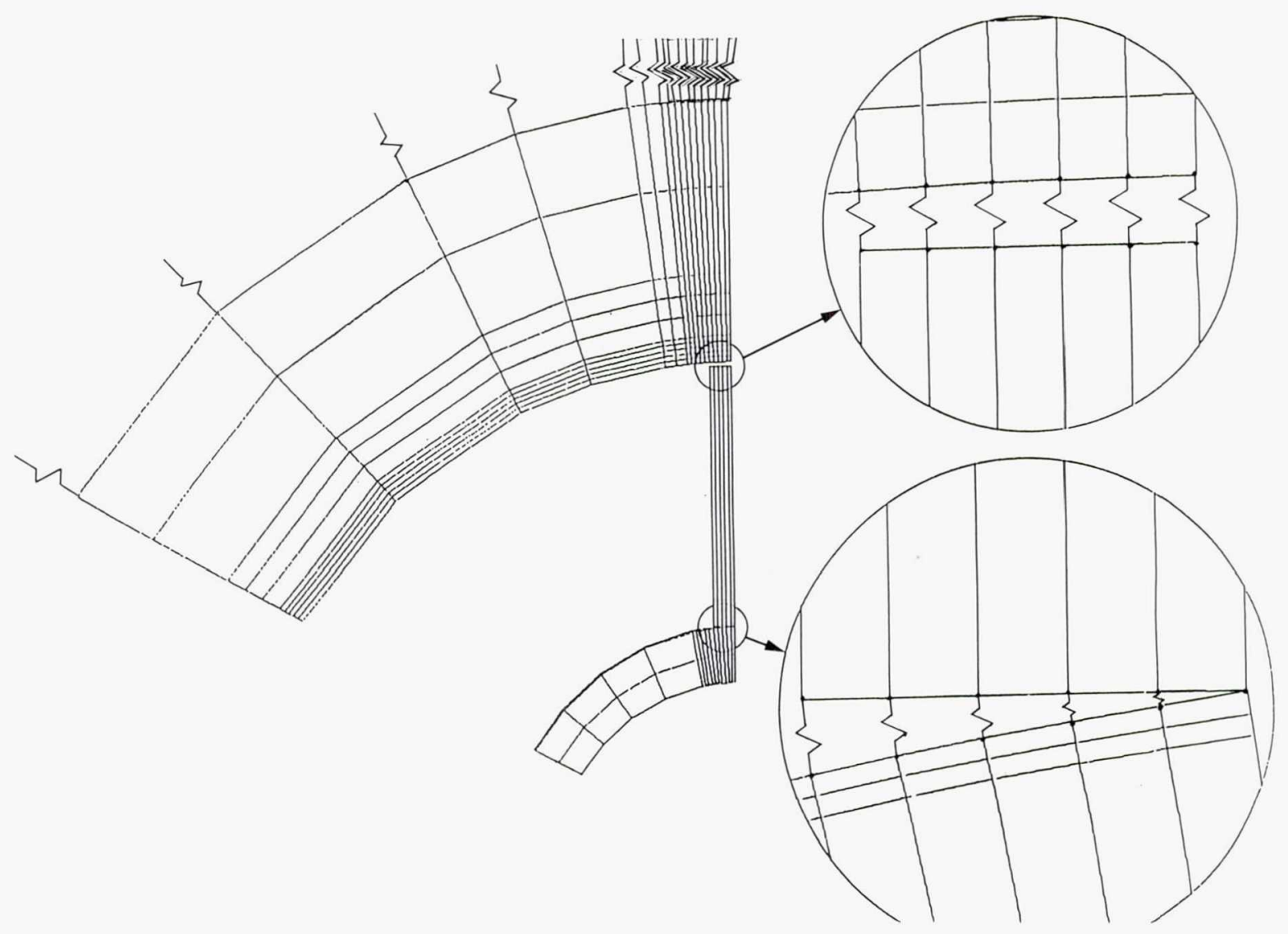

Figure 8.-Gap elements used in TWT model.

and applied constraints between end nodes to reflect the current interface condition. The total deformation of the Glidcop sleeve was $0.00267 \mathrm{~cm}(0.00105 \mathrm{in}$.). The incremental deformation of the interfaces is shown in figure 9. As the stresses in several of the materials exceeded yield, localized areas of plastic strain developed. Figure 10 shows the Von Mises stress and corresponding plastic strain values for the final die closure increment. Von Mises stress provided a convenient method of displaying the multiaxial stress state that existed in the TWT. However, all components of stress were utilized during the analysis to evaluate proper application of boundary conditions and to debug the model. The opening of the coining die was also modeled to account for springback in the compressed materials. This was accomplished by displacing the outer gap nodes (now coincident with the sleeve outer diameter) in a positive radial direction. Small displacement increments of equal size were run until the gaps representing the die/Glidcop sleeve interface were all open. This required six increments. The fabrication simulation for the traveling wave tube was then complete. Figure 11 displays the deformed geometry at the interfaces after release of the die. Figure 12 shows the Von Mises stress and plastic strain values for this state of the model.

\section{Heat Transfer Analysis}

The heat transfer analysis, using the same basic model, simulated the TWT operating condition by applying a thermal flux on the helix surfaces to represent electron bombardment and resistive losses. The heat transfer model contained no gap elements, but elements (MARC type 7) were created at the interface regions where gaps were determined to be closed. These elements used an equivalent conductivity as their only property. The equivalent conductivity was found by using the gap status information furnished by the coining analysis. A contact force was given for each closed gap element and used to calculate a contact pressure between the components at this point. Data provided by Hughes, shown in figure 13, were used to determine interface coefficients for the Glidcop/ diamond and the diamond/copper-plated tungsten interfaces as a function of contact pressure. The graph included a curve for a diamond/copper interface but not one for a diamond/ Glidcop interface. Since material testing was not feasible at this point, the diamond/Glidcop interface coefficients were determined by scaling the pressure axis of the curve by the ratio of the yield strengths of Glidcop and copper (47/6). This 

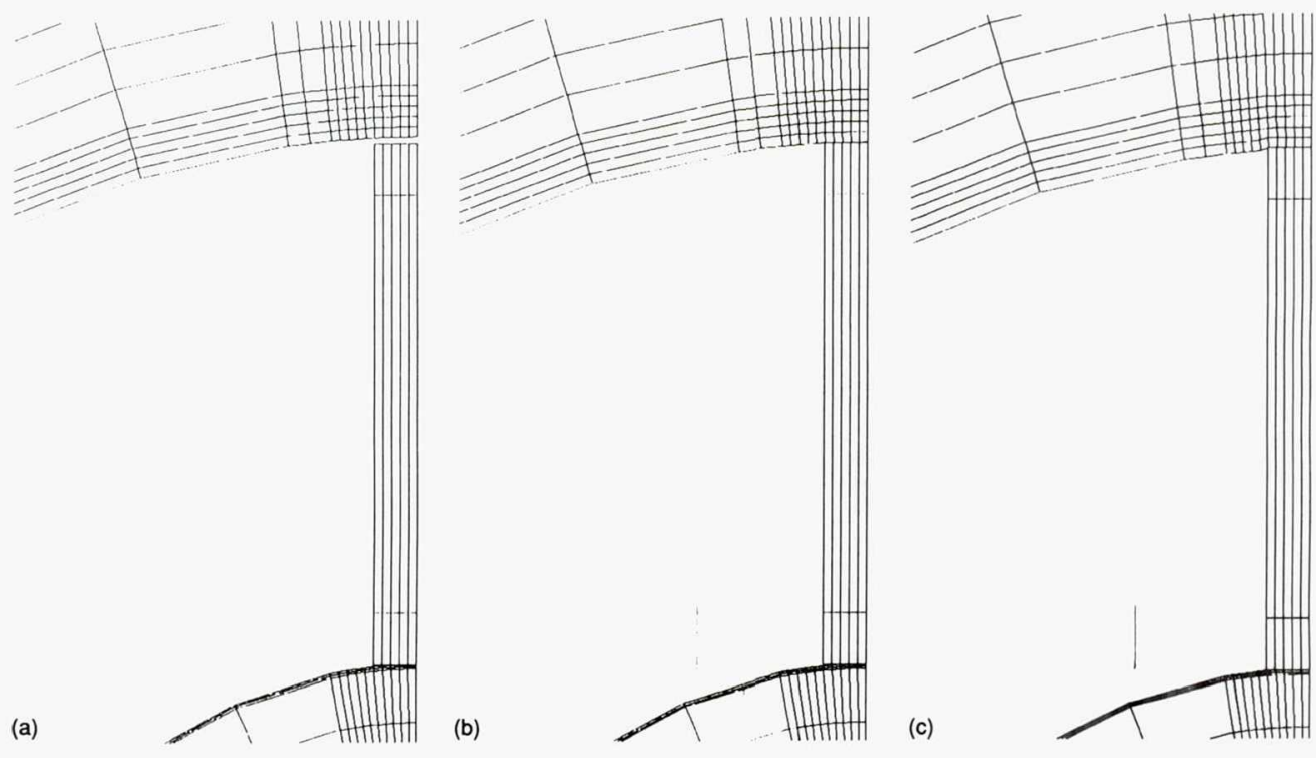

(a) Increment 1 .

(b) Increment 4.

(c) Increment 7.

Figure 9.-Incremental deformation of interfaces for die closure.

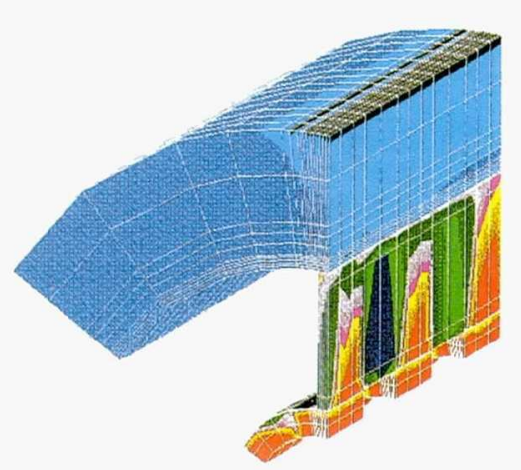

(a)

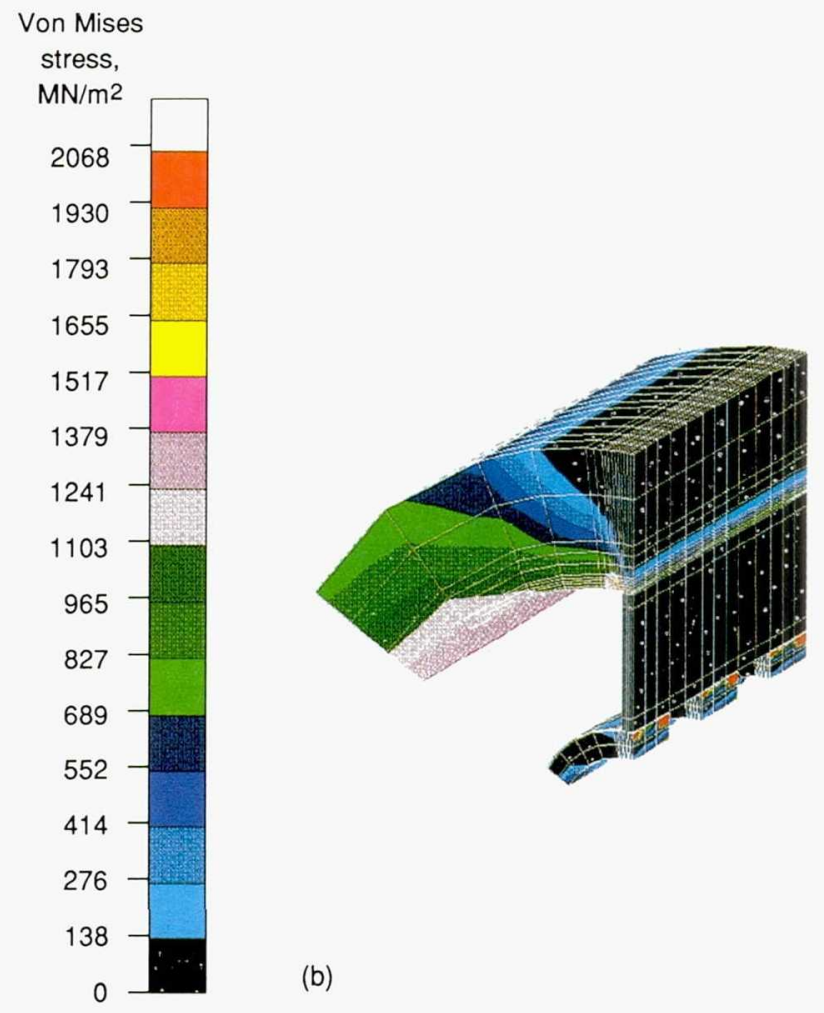

Plastic

strain

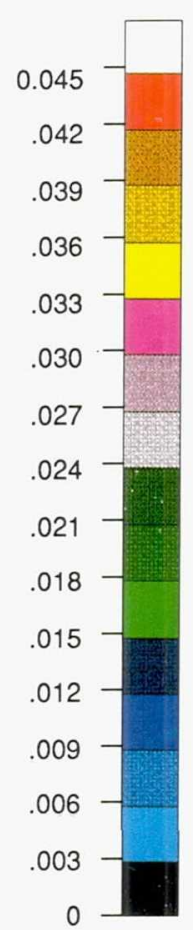

(a) Von Mises stress

(b) Plastic strain.

Figure 10.-Stress and strain for increment 7 (die closed). 

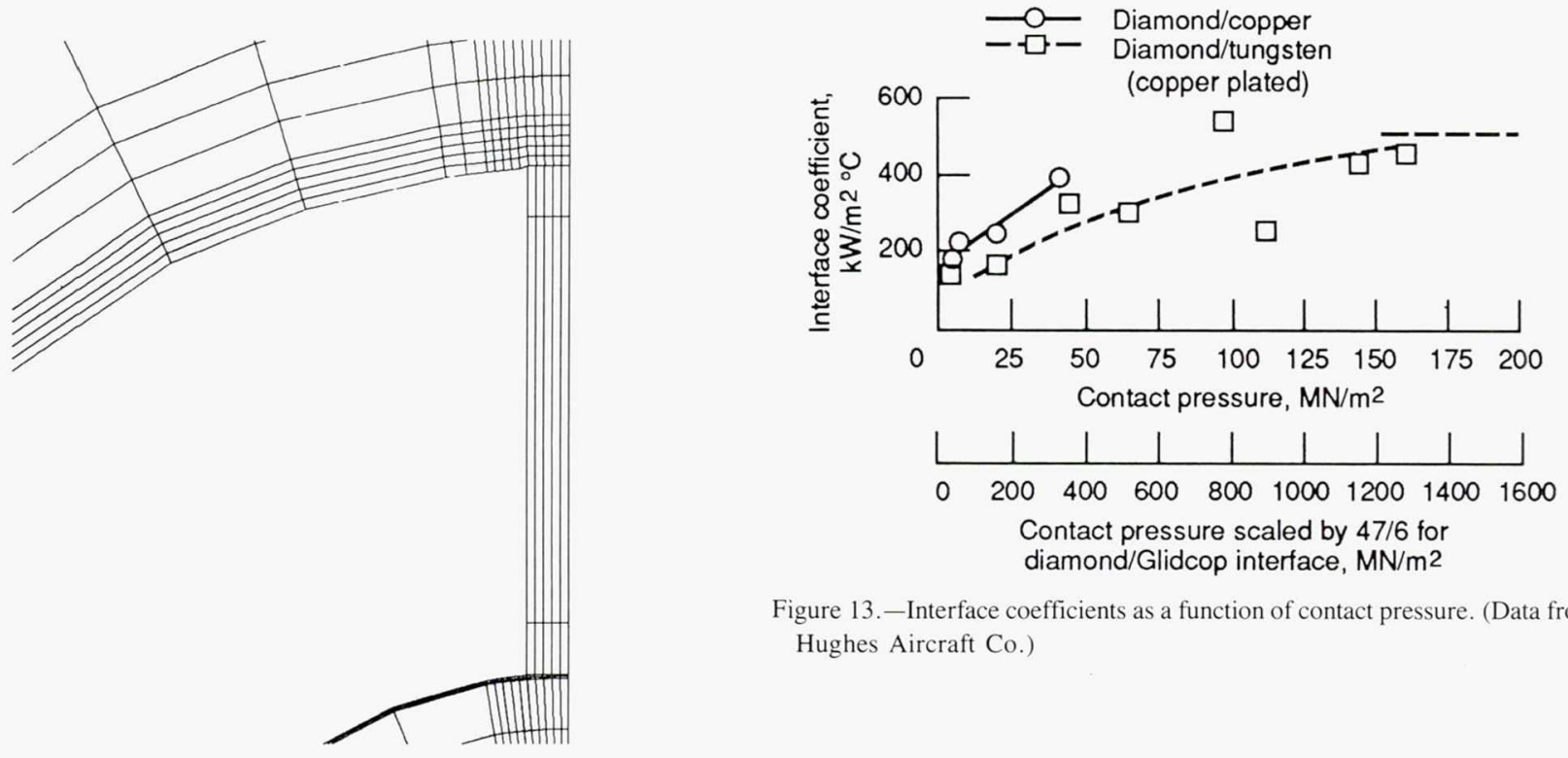

Figure 13.--Interface coefficients as a function of contact pressure. (Data from Hughes Aircraft Co.)

Figure 11.-Deformation of interfaces after die opening. Increment 13.
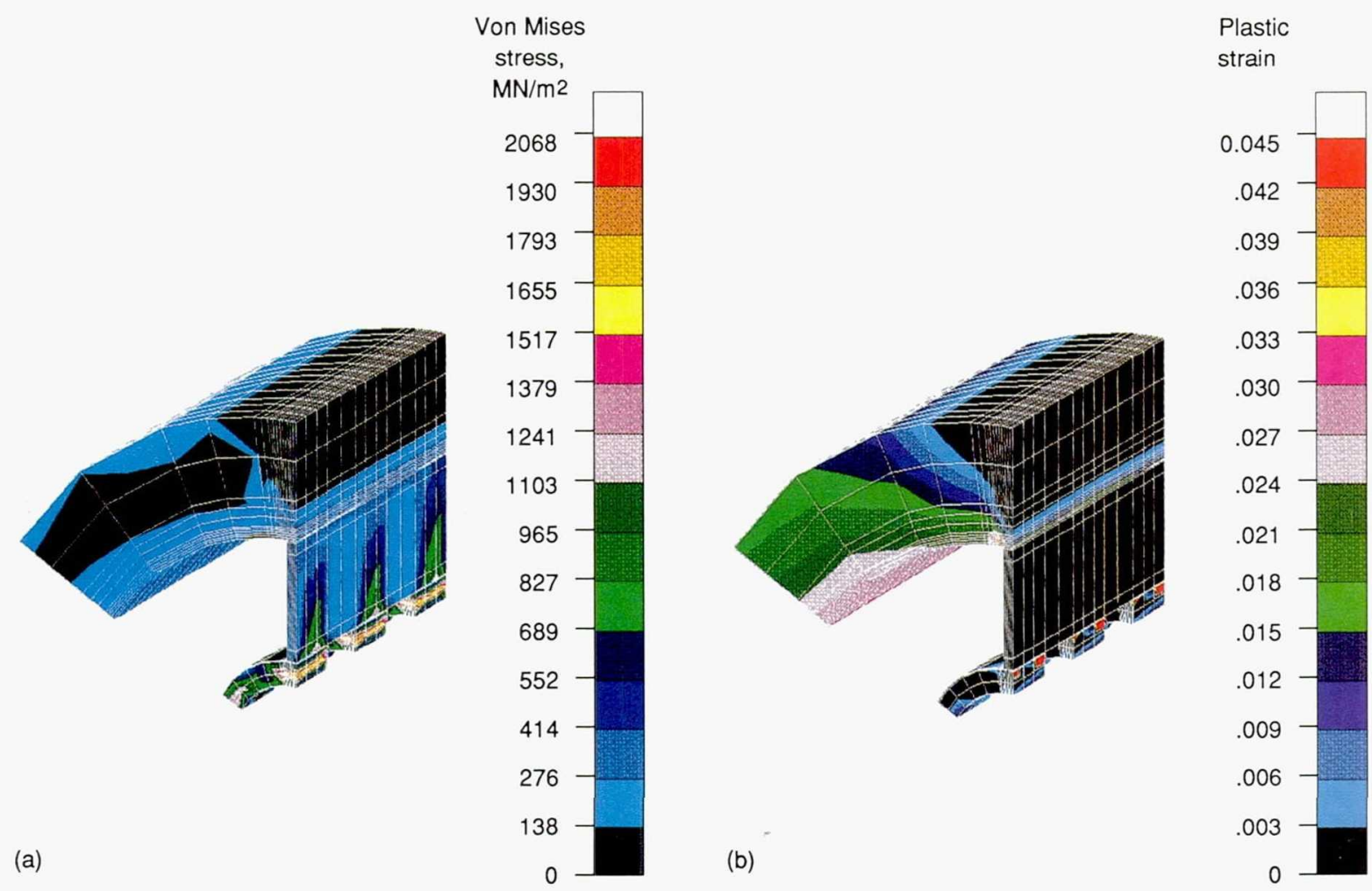

(a) Von Mises stress

(b) Plastic strain

Figure 12.-Stress and strain for increment 13 (die released). 
was a rough approximation, but literature indicates that interface coefficient is a function of yield strength (ref. 10). The curve for diamond/copper (Glidcop) was assumed to be linear, with values beyond those available being extrapolated. The curve for diamond/copper-plated tungsten was assumed to have an asymptote at $500 \mathrm{~kW} / \mathrm{m}^{2}{ }^{\circ} \mathrm{C}$. The equivalent conductivity was calculated from the equation

$$
K_{\text {eq }}=(\text { Interface coefficient }) \times h_{\mathrm{eq}}
$$

Since the heat transfer model used the original precoined geometry of the structural model, the average thickness of an interface element $h_{\mathrm{eq}}$ was the average initial distance between the two components at the interface.

The loading for the heat transfer model was accomplished by applying a thermal flux over the outer surfaces of the helix sections. The flux was varied for three different analytical cases. The boundary conditions for the heat transfer analysis assumed $Z$-direction faces to be insulated (see fig. 6). Boundary conditions for the thermal model were selected from several sources, as indicated in the following sections. The outer diameter of the Glidcop sleeve was fixed at an appropriate temperature for each case analyzed. The result of the heat transfer study was a nodal temperature distribution throughout the model.

\section{Thermal/Structural Analysis}

The next step in achieving a final temperature distribution involved both the structural and thermal models. The temperature distribution obtained from the heat transfer analysis was applied to the coined structural model in a thermal/structural analysis. Temperatures at the element integration points, provided by the output from the heat transfer analysis, were reformatted by using a simple FORTRAN program and included in the model data file. The RESTART feature was used to read in the final coined state of the model. This coined state was used as the starting point for the thermal/structural analysis. As a result, all stress from the coining simulation remained in the model, greatly influencing contact areas and pressures. A null increment (no force or displacement load, but including thermal load) was analyzed to determine contact area and pressure changes due to the component temperature changes. New equivalent conductivities were calculated for the elements at the interfaces from gap status information and inserted into the heat transfer analysis. Another temperature profile based on the new state of contact between components was then generated. Several iterations between the heat transfer analysis and the thermal/ structural analysis were required to reach a steady-state temperature distribution.

\section{Results}

\section{Coining Analysis Dimensional Correlation}

Several dimensions of TWT coining test assemblies were measured by Hughes. Two dimensions, measured before and after coining, were the inner and outer diameters of a coining sleeve. The change in the dimensions measured in the test piece was compared with the change in these dimensions predicted by the analytical coining model. The difference was 3.4 and 5.3 percent for the inner and outer diameter changes, respectively.

\section{Comparison With Breadboard Test Data}

The first set of analytical cases was performed to compare predicted temperature values with measured test data. Hughes ran several tests on breadboard components of the $953 \mathrm{H}$ TWT . These breadboard tests were completed on specific hardware that was intended to measure particular thermal parameters. In one of these tests the input power was varied and the temperatures of several components were recorded. Figure 14 shows the comparison of the measured helix temperature with the helix temperature predicted by the analysis. Also shown in figure 14 is the measured temperature of the outer diameter of the Glidcop sleeve, based on a mounting platform temperature of $50{ }^{\circ} \mathrm{C}$, for the power levels shown. This sleeve temperature was used in the analysis as a boundary condition. The analytical values ran about 20 percent cooler than the measured temperatures. This may be attributed to the fact that the model is an idealization with respect to geometry, symmetry, surface finish, and loading. The real parts are not exactly round, as in the mathematical representation in the $\mathrm{FE}$ model. Also, all of the TWT components have tolerances that are not reflected in the model, and these may reduce interface contact over some portion of the TWT. The lack of precision involved in determining interface coefficients also adds a

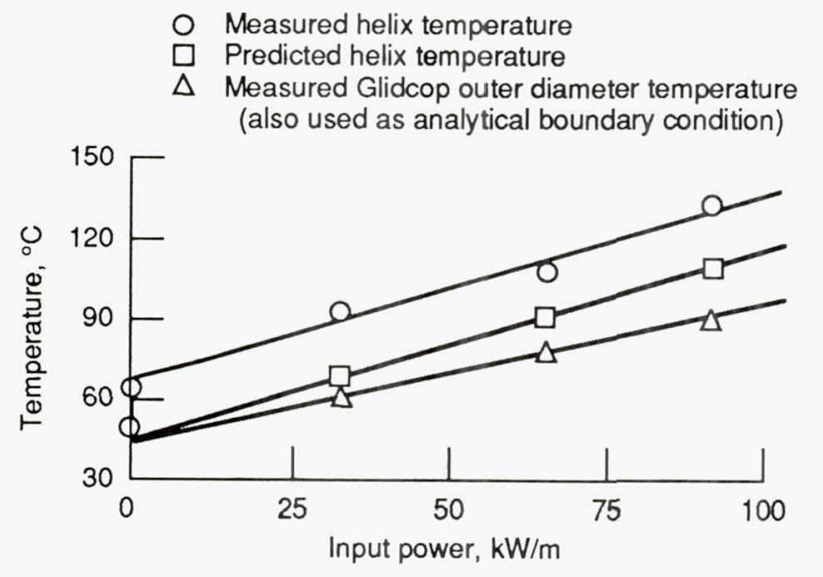

Figure 14.-Comparison of analytical temperature values with test results. 
degree of uncertainty to the predicted temperatures. Furthermore, owing to the breadboard test structure, some averaging of the measured helix temperature is required. These factors may all contribute to the more "efficient" transfer of heat in the FE model.

\section{Normal Operation}

In the next analytical case normal operation of the TWT was simulated. A thermal flux value was applied to the helix, based on input power data provided by Hughes and shown in figure 15 . Since the model was constructed to represent the hottest end of the helix, the thermal flux distributed over the outer surfaces of each $60^{\circ}$ helix section was based on $6.6 \mathrm{~W}$ of input power over the last $0.635 \mathrm{~cm}(0.25 \mathrm{in}$.) of the helix. The outer diameter of the Glidcop sleeve was fixed at a temperature of $153{ }^{\circ} \mathrm{C}$. This temperature was obtained from a three-dimensional heat transfer analysis, completed by Hughes (ref. 11), that used a conservative mounting platform temperature of $85^{\circ} \mathrm{C}$. The maximum temperature achieved in the helix was $161{ }^{\circ} \mathrm{C}$. The final temperature distribution is shown in figure 16 .

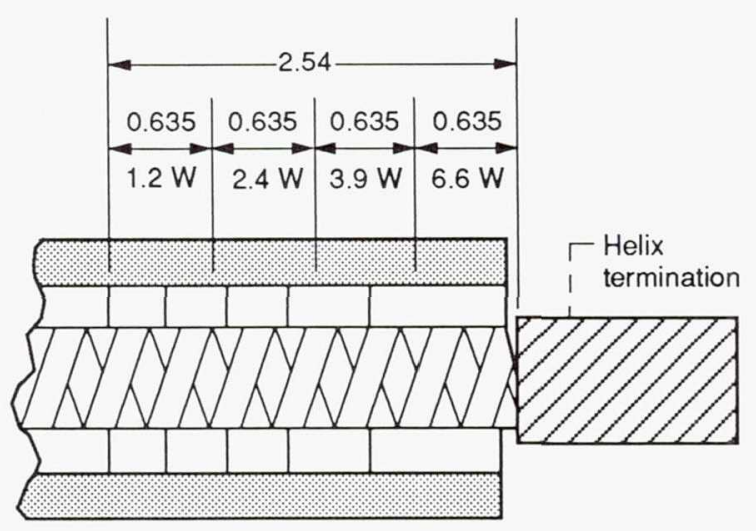

Figure 15.-Power dissipation along last $2.54 \mathrm{~cm}$ of helix during normal operation ( $75 \mathrm{~W}$ RF output). Dimensions are in centimeters. (From Hughes Aircraft Co.)

A previous two-dimensional analysis of the $953 \mathrm{H}$ TwT, also performed by Hughes and based on the previously stated bpundary conditions, showed a maximum helix temperature of $198^{\circ} \mathrm{C}$. This two-dimensional analysis also did not attempt

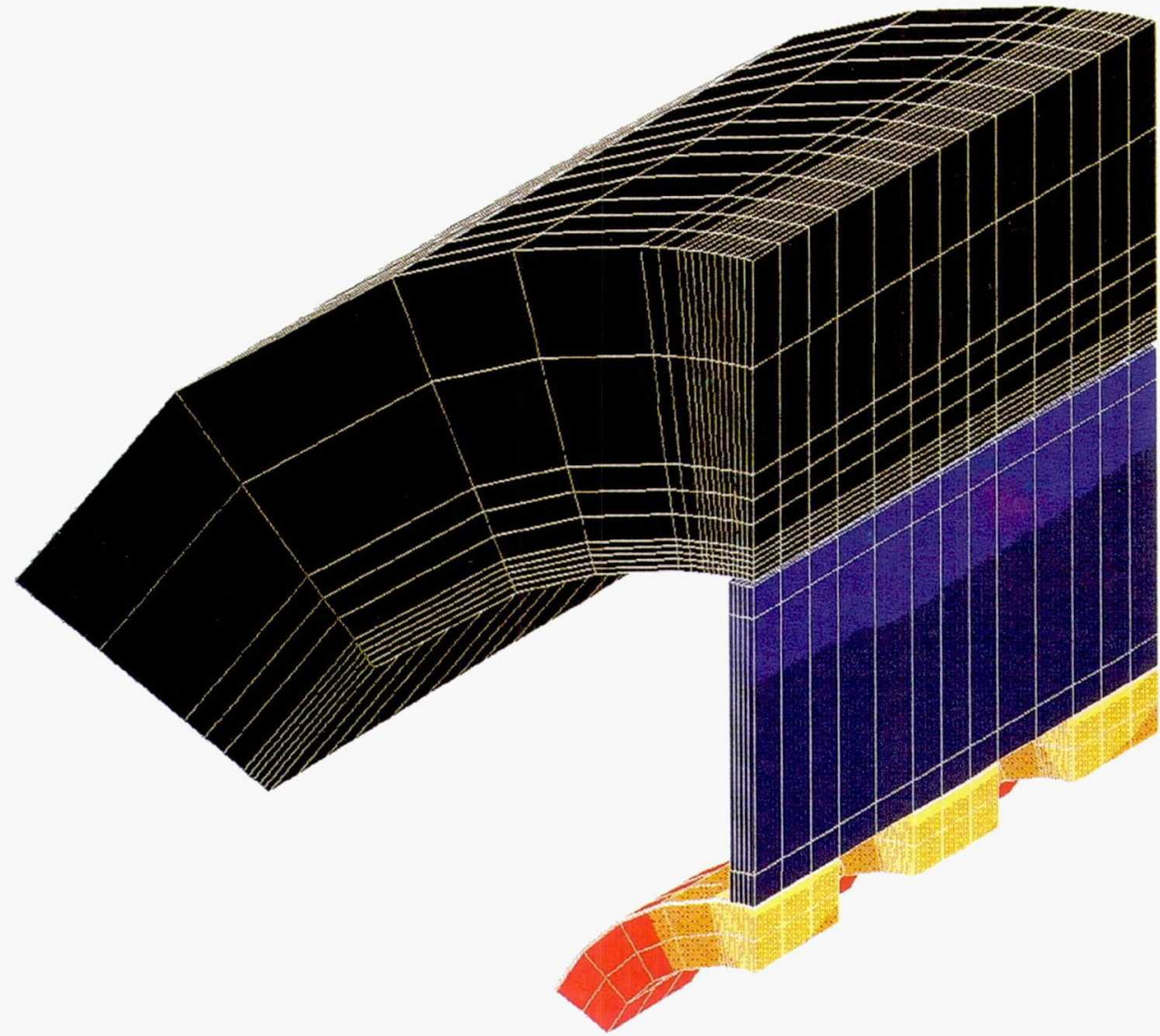

Temperature,

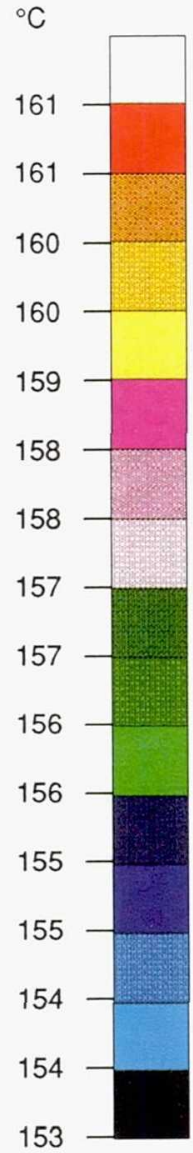

Figure 16. - Temperatures throughout model for normal operation. Input power, $67 \mathrm{~kW} / \mathrm{m}$; temperature at Glidcop outer diameter, $153{ }^{\circ} \mathrm{C}$. 

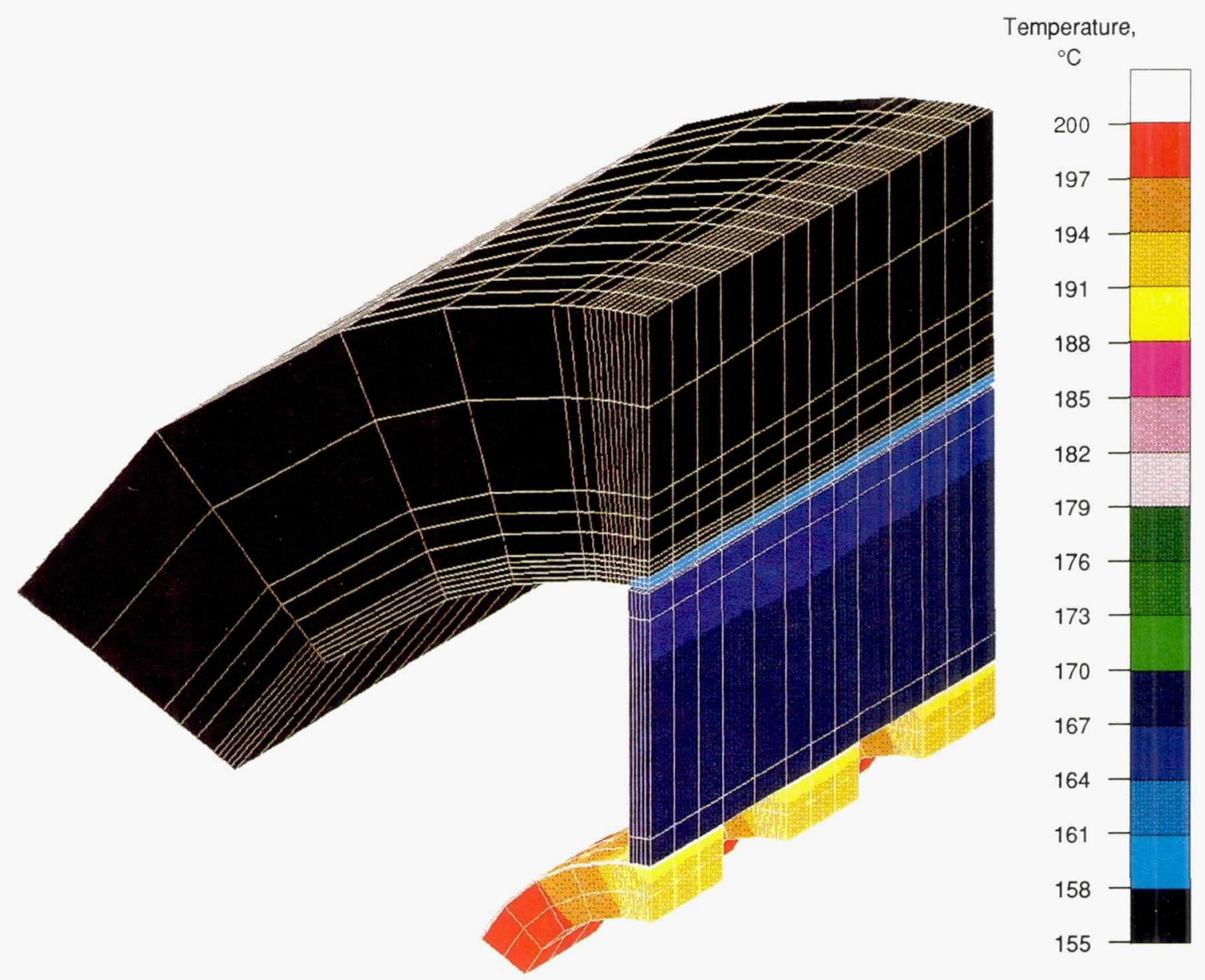

Figure 17.-Temperatures throughout model for failure analysis. Input power, $218 \mathrm{~kW} / \mathrm{m}$; temperature at Glidcop outer diameter, $155^{\circ} \mathrm{C}$.

to model the bakeout process; however, it was assumed that all stresses in the model due to coining were relieved during the bakeout. This is considered an extremely conservative assumption; it reduces the contact pressure at the interfaces and decreases the effectiveness of the thermal path, increasing the maximum temperature. The actual maximum temperature of the helix during normal operation may be bounded on the upper and lower ends by the two-dimensional and threedimensional analytical values, respectively. The threedimensional analytical method is preferred, since the analysis involves fewer geometric assumptions and includes the effects of residual stresses and since the results correlate well with available coining test data.

\section{Ultimate Power Loading}

The last case analyzed for this model was a prediction of ultimate power loading for the TWT. In order to predict operational instability or a thermal breakdown power for the $953 \mathrm{H}$ TwT, a helix coating temperature of $200{ }^{\circ} \mathrm{C}$ was assumed to initiate the onset of a significant amount of creep in the copper (ref. 12). This creep would cause plastic deformation resulting in irreversible deterioration in TWT performance. The input power level applied to the helix sections of the model was based on $218 \mathrm{~kW} / \mathrm{m}$. This value was determined by using the curves of figure 14 to extrapolate the approximate input power and Glidcop outer diameter temperature for a helix temperature of $200{ }^{\circ} \mathrm{C}$. With these values provided as input, several iterations were required to converge to a solution. Figure 17 displays the temperature distribution achieved. Hughes has determined, through testing, that the TWT loses thermal stability at $178 \mathrm{~kW} / \mathrm{m}$. Loss of thermal stability means that a measured temperature for the TWT at a particular power level did not repeat after the TWT was allowed to cool and the same power level was reapplied.

\section{Conclusions}

The simulation of the fabrication and operation of the $953 \mathrm{H}$ traveling wave tube (TWT), using a nonlinear, threedimensional finite-element analysis, shows great potential to aid in future TWT development efforts. Helix temperatures and 
sleeve dimensions predicted by this analysis compared favorably with measurements taken by Hughes. An ultimate power level for the TWT was predicted to be $218 \mathrm{~kW} / \mathrm{m}$. In testing, this TWT lost thermal stability at $178 \mathrm{~kW} / \mathrm{m}$. Further examination of these analytical results may lead to the development of a correction factor to be applied to interface values to account for surface finish and manufacturing tolerances, thus making temperature and power predictions more realistic.

This analytical effort used many nonlinear features of the MARC finite-element code. It included elastic, plastic, and thermal material properties, temperature-dependent properties, and gap elements. The loading was done incrementally and utilized the RESTART option, reducing the computer time needed. Even though the fabrication of a new coined, diamondrod TWT was simulated, the analytical methodology developed in this effort is generic in nature and is adaptable to a wide variety of fabrication methods, such as heat shrinking, pressure fitting, and cold compression. Component dimensions and component materials can easily be varied. Also, other helix geometries, such as ring bar and wound wire, can be investigated. This analytical technique is highly significant to the traveling-wave-tube industry because it has the potential to effectively predict the thermal and structural characteristics without building and testing numerous TWT prototypes.

Lewis Research Center

National Aeronautics and Space Administration

Cleveland, Ohio, December 12, 1990

\section{References}

1. Aldana, S.L.; and Tamashiro, R.N.: K-Band TWT Using New Diamond Rod Technology. AIAA International Communication Satellite Systems Conference and Exhibit, 13th, Los Angeles, CA, Mar. 11-15, 1990, Technical Papers, AIAA, Washington, D.C., 1990, Pt. 2, pp. 766-770. (Also AIAA Paper 90-0870, Mar. 1990.)

2. Tamashiro, R.N.; and Aldana, S.L.: 60 Percent Efficient K-Band TWT Using New Diamond Rod Technology. International Electron Devices Meeting, Washington, D.C., Dec. 3-6, 1989, IEEE, 1989, pp. 8.1.1 to 8.1 .4 .

3. Tamashiro, R.N.: The $20 \mathrm{GHz}, 75$ Watt Helix Traveling Wave Tube for Space Communications. NASA CR-168271, 1984.

4. Three-Dimensional Arbitrary Distored Cube-Element 7. MARC Element Library, MARC Analysis Research Corporation, Rev. K.3, 1988, Vol. B, pp. B7.1-1 to B.7.1-4.

5. Restart Option. Program Input, MARC Analysis Research Corporation, Rev. K.3, 1988, Vol. C, pp. C3.3-29 to C3.3.-31.

6. Glidcop Grade AL-15 Dispersion Strengthened Copper Technical Data. SCM Metal Products, Cleveland, OH

7. Boundary Conditions. User Information Manual, MARC Analysis Research Corporation, Rev. K.3, 1988, Vol. A, pp. A8-20 to A8-34

8. Friction and Gap Element-Element 12. MARC Element Library, MARC Analysis Research Corporation, Rev. K.3, 1988, Vol. B, pp. B12.1-1 to B12.1-6.

9. Input of Gap Direction and Closure Distance Subroutine GAPU. User Subroutines and Special Routines, MARC Analysis Research Corporation, Rev. K.3, 1988, Vol. D, pp. D1.39-1 to D1.39-2.

10. Rohsenow, W.M.; Hartnett, J.P.; and Ganic, E.N., eds.: Handbook of Heat Transfer Fundamentals, McGraw-Hill, 1985, pp. 4-17 to 4-25.

11. Norenberg, K.A.: $953 \mathrm{H}$ Traveling-Wave Tube Diamond Circuit Mechanical Analysis. Hughes Aircraft Co., 1988.

12. A Survey of Properties and Applications, OFHC Brand Copper. AMAX Copper, Inc., New York, 1974, p. 25. 


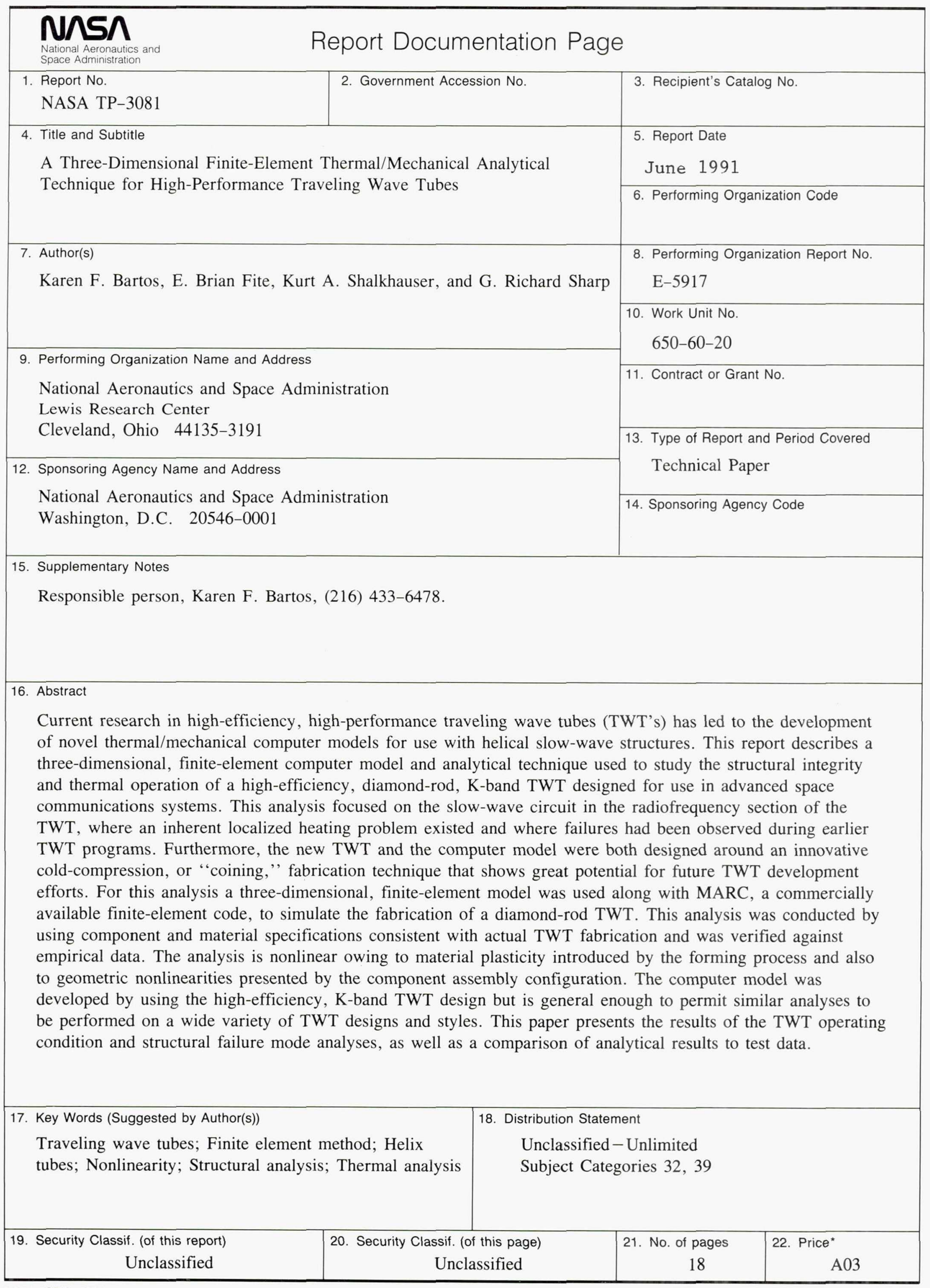

